portunity presents itself to the Editors of the Boston Medical and Surgical Journal to put in practice the Christian maxim, "Do unto others as you would they should do unto you," by the insertion of the antidote in the pages of the journal that circulated the bane.

Very respectfully, yours, \&c.

New Orleans, Jan. 19, 1859.

Edward Jenner Coxe, M.D.

\title{
SURGICAL CLINIQUE AT CASTLETON MEDICAL COLLEGE.
}

Fali TenM, 1858-E. K. Sanbonn, M.D., Prof. of Surgeny.

[Reported for the Boston Medical and Surgical Journal by WrLLARD A. CurLdr, Demonstrator of Anatomy.]

The clinique, commenced the last year, was continued during the fall session of lectures with increased success. A large number of patients presented themselves for medical and surgical treatment, and in the surgical department, under the charge of Prof. Sanborn, were a number of cases requiring operations of unusual magnitude and interest, a brief abstract of which I give below.

\section{AMPUTATIONS.}

I.-Middle Finger of the Right Hand, amputated near the metacarpal joint, for the relief of a deformity caused by a wound from a circular saw. The patient, Mr. D. H., was a young man of 25 , and made a rapid recovery.

II.-Middle Finger of the Left Hand, amputated for neuralgic disease, following a wound from a straw-cutter. The patient in this case (Mrs. N., aged 45) was a great sufferer from neuralgic pains, which originated in a wound which had been healed some months. Amputation was advised, as offering the best chance of relief. As the lady was from a distance, the result has not been learned.

III.-Amputation of the Thigh in the Upper Third,for ex. tensive Scrofulous Disease.-This case was an extraordinary one, as regards the extent of the disease. The original malady was apparently suppurative inflammation of the knee-joint. The ulceration by progressire destruction of the soft parts, at the time of the operation, had reached to within three inches of the hip-joint. The patient had been confined to the bed for two years, and was extremely reduced. Hectic symptoms had been developed within a short time. 'The lungs were apparently sound, and the appetite good. Prof. Sanborn remarked, before operating, that it was very doubtful if all the diseased tissue could be removed, except by amputation at the hip-joint. But as in the present condition of the patient this operation would probably be fatal, he should pro. ceed to operate as high up as possible, without disarticulating, and finish the operation according as the condition of the bone indicated. The paticnt bcing put under the influence of sulphuric 
ether, the bone was exposed by anterior and posterior flaps, and sawed through just below the trochanters. The bone was found to be sound, but the muscular tissue of the posterior flap indurated, with sinuses cxtending upward toward the joint. After arresting the hæmorrhage, which was very profusc, a large mass of diseased tissuo was carefully dissected out, and the wound dressed in the usual manner (water dressing). The patient did not rally from the immediate effects of the operation for some hours, but finally made a good recovery, without any unusual symptoms.

IV.-Amputation at the Shoulder-Joint; Gun-Shot Wound.The patient, D. R., was a young man aged 20 . In carelessly handling a loaded gun, the whole charge passed through the left arm, just below the axilla, fracturing the bone, carrying away the bloodvessels, \&c. \&c. Before relief could be obtained, he had bled nearly to death. He was scen by Prof. Sanborn six hours after the accident. The patient was then in a state of collapse from hæmorrhage. An examination of the wound showed the limb to be hopelessly injured, though the condition of the patient was such as offered very little hope that he would rally sufficiently to suffer amputation. The details of this case are quite interesting in a physiological point of view, but my limits will only allow me to say, that a systematic plan of administration of food was adopted, to supply the loss of blood and bring about reaction if possible. It was on the third day after the accident that the pulse first became perceptible at the wrist. During that time the patient had taken by the mouth and per anum three gallons of beef-tea, chick. en-broth, \&c., besides a pint of milk punch, and brandy and water in considerable quantities. During the third day reaction became fully established, the patient was put under the influence of ether, and the arm removed at the shoulder-joint. The operation was well borne, and the patient did well until the fifth day from the operation, when involuntary contractions of the pectoral muscles of the uffected side began to annoy him, and gradually developed into unequivocal tetanus, which was fatal in thirty hours from the first attack. After the first tetanic symptoms, the patient was kept under the influence of ether till death occurred.

\section{CANCERS.}

I.-Scirrhous Tumor of the Breast, of two years' standing.Mrs. M., 38 years of age. The tumor in this case was very large, with a small point of ulceration near the nipple. The axillary glands were not affected, and the general health good. The growth of the tumor had of late been quito rapid. The tumor was removed in the usual manner, a considerable portion of discolored skin being embraced by the incision. Prof. Sanborn is in faror of removal of all cases of cancer of the breast, where no cachexia is manifest, and thinks enlargement of the axillary glands (when they can bo safely remored) no ohjection to the opcration. In suppcrt 
of this opinion, he cited the case of a lady in Massaclusetts from whom a cancerous breast in an adranced stage of the disease had been removed, together with enlarged axillary glands, and whom he had lately seen in perfect health, eight ycars subsequent to the operation.

II.-Cancer of the Lower Lip.-Mr. B. W., aged 35. About one half of the lip was removed by a V-shaped incision, and the wound closed by one twisted and four interrupted sutures. The pin was removed on the third day, and all the sutures on the fourth. On the twelfth day the patient was discharged well, with no noticeable deformity.

III.-Extirpation of Testicle for Cancerous Discase.-Mr. N. N., aged 45 years. The gland in this case was enormonsly enlarged, and there was also effusion into the tunica vaginalis to a considerable extent. The patient being put under the influence of ether, a trocar was thrust into the scrotum, and about cight ounces of straw-colored serum drawn out. The scrotum was then laid open, and the gland dissected out, the cord being transfixed by a tenaculum before division. Sereral ligatures were required both on the arteries of the cord and in the scrotum. The testicle weighed thirty-cight ounces after remoral, and examination showed the disease to be encephaloid cancer. Recovery took place without accident, as I have learned from Dr. Allen, of Middlebury, who kindly presented the case.

\section{MISCELLANEOUS CASES.}

I.-Necrosis of the Femur, of eleven years' standing.-I. M., aned 27 years. 'The thigh of the patient was very much enlurged, with numerons openings on each side, communicating with a cavity enclosing dead bone. An incision, six inches in length, was made on the outer side of the thigh, exposing the bone. The blecding from the vessels of the thickencd periosteum was severe, and much delayed this part of the operation. A trephine was applied to the enclosing bone, and the opening thus made was enlarged by a metacarpal saw and a common chisel. A tubnlar-shaped sequestrum was thus exposed and extracted, in pieces from three to five inches in length. The wound, after being thoroughly washed ont, was filled with lint, which was kept saturated with the lotion of the chloride of soda, and this continued as long as the suppuration was profuse, which was sereral weeks. $\Lambda t$ the present writing (Dec. 13 th) the wound is nearly closed.

A case of acute necrosis of the tibia in a clild of 10 years was presented the same day, but delay was advised in consequence of the degree of inflammation present.

II._Double Hare-Lip._Master — 6 years old. The case presented the usual features of this species of deformity, though the age was considered as an unlortumate one for the pertormanee of so painful an operation. 'The little patient, however, showed 
a marvellous degree of pluck, and offered no serious obstacle to the performance of the operation, thongh no anxsthetic was used. The operation was complicated, and difficult to describe. No atteinpt was made to bring the middle portion down on a line with the rest of the lip, but it was cut to a point, and enibraced by the lateral portions of the lip, so that the scar left is shaped like the capital Y. Malgaigne's plan of preventing the slight notch, usually seen in the freo border of the lip after operation, was adopted in this case with success. The parts were brought together with twisted sutures, and dressed with collodion. The pins were carefully withdrawn in forty-eight hours; the other dressings remained until the fifth day, when union was found complete.

III._Cataract; Operation by Depression.-Mr. L. B., aged 84. The pationt in this case was totally blind, from cataracts which had tirst affected the eyes, ten years previous. The general health was remarkably good, the eyes full and large, and nothing but age contra-indicated an operation. It was, however, unsuccessful. Sphacelus of the cornea occurred immediately. Fortunately, the operation or its consequences caused very little pain. The cye not operated upon was unaffected.

IV.-Tenotomy.-D. A. S., a little girl four years old, with permanent coutraction of the knec-joint. The leg in this case was permanently fixed at right angles with the thigh, said to have fol. lowed an attack of fever. The joint was enlarged, but not tender to the touch, and there was evidently no anchylosis. The tendons of the liam-string muscles were divided subcutanconsly, and the limb straightened forcibly, and so kept for two weeks by a straight splint. Subsequently an adjustable angular splint was applied, and the patient made to walk with the leg in a straight position. A gum bandage has been substituted for the splint, under which treatment the child is gradually improving.

.V.-Large Vascular Tumor on the Right Side.-Infant child of Mr. P. The tumor was originally a navus maternus. It had gradually taken the form of a tumor, and was at the time of operation as large as an English walnut, and growing steadily. No pulsation could be detected. It was removed in the manner recommended by Liston. The base of the tumor was circumscribed by an incision extending through the skin only. Tiro necdles were then thrust through, in a crucial form, and under them a strong ligature was tightly drawn in such a manner as not to embrace the skin. The ligature was tightened twice afterward, and the tumor finally came off, without bleeding, in ten days.

Cases of encysted and fatty tumors were also operated on, and many cases of minor importance treated, instructive to the student, but of no particular interest to the readers of the JourNaL, 